\title{
Expression, Purification and Crystallization of Wheat Profilin (Tri a 12) ${ }^{\dagger}$
}

\author{
Christina Ecker, ${ }^{a}$ Peter Forstenlechner, ${ }^{\mathrm{b}}$ Dalibor Milić, ${ }^{\mathrm{c}}$ Karin Hoffmann-Sommergruber, ${ }^{\mathrm{b}}$ \\ Margit Cichna-Markl, ${ }^{a}$ and Dubravka Matković-Čalogovićc,* \\ ${ }^{a}$ Department of Analytical Chemistry, University of Vienna, Währinger Straße 38, A-1090 Vienna, Austria \\ ${ }^{\mathrm{b}}$ Department of Pathophysiology and Allergy Research, Medical University of Vienna, \\ Währinger Gürtel 18-20, A-1090 Vienna, Austria \\ ${ }^{\mathrm{c}}$ Laboratory of General and Inorganic Chemistry, Department of Chemistry, Faculty of Science, University of Zagreb, \\ Horvatovac 102a, HR-10000 Zagreb, Croatia
}

RECEIVED OCTOBER 25, 2010; REVISED JUNE 14, 2011; ACCEPTED JUNE 16, 2011

\begin{abstract}
Profilin from wheat (Triticum aestivum) has been identified as an allergen (Tri a 12). The recombinant $14 \mathrm{kDa}$ protein was produced in Escherichia coli, purified and crystallized using the hangingdrop vapour-diffusion method. A diffraction-data set was collected in-house from a single crystal to a resolution of $3.3 \AA$. The crystals belonged to space group $P 3_{2} 21$, with unit-cell parameters $a=b=58.9 \AA$, $c=82.5 \AA, \alpha=\beta=90^{\circ}$ and $\gamma=120^{\circ}$. (doi: $10.5562 / \mathrm{cca} 1790$ )
\end{abstract}

Keywords: wheat profilin, expression, crystallization, food allergy

\section{INTRODUCTION}

Ingestion of wheat (Triticum aestivum) can induce immune-mediated adverse food reactions such as celiac disease or IgE mediated Type 1 allergies in predisposed individuals. The prevalence of wheat induced food allergy is low in adults. However, in young children wheat is one of the major causes of food allergy. ${ }^{1}$ Respiratory allergy to wheat flour, affecting particularly persons working at bakeries and therefore named baker's asthma, is one of the most common causes of occupational asthma. ${ }^{2}$

To date, ten allergens have been identified from wheat by two-dimensional gel electrophoresis, immunoblotting using sera from allergic patients and mass spectrometry $^{3-6}$ as well as by screening cDNA libraries displayed on phage surface ${ }^{7}$ (www.allergen.org). Recently, wheat profilin, designated Tri a 12, has been found to be recognized by specific IgE antibodies in patients suffering from baker's asthma, wheat induced food allergy and also in patients with grass pollen allergy. ${ }^{8}$ Profilins are one of the most prevalent plant protein families causing IgE mediated reactions. ${ }^{9-11}$ These monomeric proteins with a molecular weight of 12 to $15 \mathrm{kDa}$ are ubiquitous components of the eukaryotic skeleton. ${ }^{12}$ Profilins are actin binding proteins, their main function being regulation of dynamics of actin polymerization during processes such as cell movement and signal transduction. ${ }^{13}$
The birch pollen allergen, Bet $\mathrm{v} 2$, was the first allergenic profilin identified. ${ }^{14}$ In the meantime, members of this protein family have been identified in a variety of fruits and vegetables. ${ }^{15}$ Since profilin sequences are highly conserved among plants, individuals who are sensitized to profilin commonly show allergic symptoms to a large number of unrelated plants. Knowledge about the three-dimensional structure of these allergenic proteins is necessary to gain information on the surface structure that in turn is necessary to predict crossreactivity. However, in contrast to other plant profilins, ${ }^{16,17}$ the three-dimensional structure of Tri a 12 has not been resolved yet. The aim of the present study was to crystallize Tri a 12 expressed from E. coli and to perform preliminary X-ray crystallographic analysis.

\section{EXPERIMENTAL}

\section{Cloning of Tri a 12}

Total RNA was isolated from two days old wheat sprouts using the Plant RNA extraction kit (SigmaAldrich, Steinheim, Germany). Complementary DNA synthesis was performed using $3 \mu \mathrm{L}$ of total RNA and an oligo-dT primer T25NN according to standard protocols. Subsequently, standard PCR was performed using gene specific primers with design based upon the wheat profilin sequence deposited in Genbank

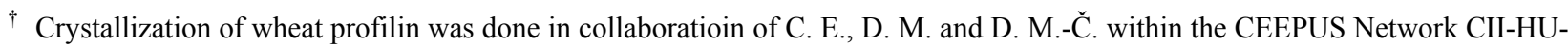
0010-04-0910.

* Author to whom correspondence should be addressed. (E-mail: dubravka.matkovic@chem.pmf.hr)
} 
Table 1. Crystal parameters and data-reduction statistics

\begin{tabular}{ll}
\hline Space group & $P 3_{2} 21^{(\mathrm{a})}$ \\
\hline Unit-cell parameters & \\
$a / \AA=\mathrm{b} / \AA$ & 58.9 \\
$c / \AA$ & 82.5 \\
$\alpha /{ }^{\circ}=\beta /{ }^{\circ}$ & 90 \\
$\gamma /{ }^{\circ}$ & 120 \\
Resolution / $\AA$ & $51.4-3.30(3.42-3.30)$ \\
Unique reflections & $4807(486)$ \\
Redundancy & $7.4(7.4)$ \\
Completeness / \% & $99.3(100.0)$ \\
$\langle I / \sigma(I)\rangle$ & $10.37(1.60)$ \\
$R_{\text {int }} / \%$ & $13.7(50.4)$ \\
\hline
\end{tabular}

(a) Values in parentheses are for the highest resolution shell.

(AccNr.: X89827; gene-specific primer forward: 5'-ATG TCGTGGAAGGCGTACGTCGA-3’; gene specific primer reverse: 5'-AGTAACCCTGATCGATCAGGT AATC-3'). The PCR product (396 bp) was ligated into the pCR2.1-TOPO vector (Invitrogen, Carlsbad, USA). Competent TOPO10 E. coli cells were transformed with the resulting plasmid. Sequencing of the inserts was performed using the Epicentre Biotech SequiTherm EXCEL II Long Read L-C Kit and analyzed by an automatic sequencer (Licor Sequencer 4000L, Li-COR, Biosciences $\mathrm{GmbH}$, Bad Homburg, Germany). Sequence analysis was performed using LICOR Image Analysis V4.0, LICOR ALIGN IR V2.0 and ClustalX software. $^{18}$

\section{Expression and Purification of Recombinant Wheat Profilin}

Tri a 12 DNA was amplified with gene specific primers designed with NdeI and EcoRI restriction sites (forward primer: 5'-GGGCATATGTCGTGGAAGGCGTAC3'; reverse primer: 5'-CCCGAATTCTTAGTAACCC TGATCGA-3'; restriction sites are underlined). The PCR product was digested with the respective restriction-nucleases (Fermentas GmbH, St. Leon-Rot, BadenWürttemberg, Germany) and ligated into the T7 based expression vector pET17b and competent $E$. coli $\mathrm{BL} 21$ (DE3) cells were transformed.

Single colonies were grown in LB medium containing $0.1 \mathrm{mg} \mathrm{mL}^{-1}$ ampicillin overnight at $30^{\circ} \mathrm{C}$. Protein expression was induced by addition of $0.4 \mathrm{mmol} \mathrm{L}^{-1}$ isopropyl- $\beta$-D-thiogalactopyranoside (IPTG) and the incubation was continued for 4 hours at $30^{\circ} \mathrm{C}$.

Cells were harvested and disrupted with lysis buffer $\left(50 \mathrm{mmol} \mathrm{L}^{-1} \mathrm{NaH}_{2} \mathrm{PO}_{4}, 300 \mathrm{mmol} \mathrm{L}{ }^{-1} \mathrm{NaCl}\right.$, $10 \mathrm{mmol} \mathrm{L}^{-1}$ imidazole; $\mathrm{pH}=8$ ) and French pressing. Subsequently, the lysate was centrifuged at $15000 \mathrm{~g}$ for 15 min at $4{ }^{\circ} \mathrm{C}$. Recombinant Tri a 12 was obtained from the supernatant. The recombinant protein was purified by a single purification step on a column of poly-L-proline (Sigma-Aldrich) coupled to CNBractivated Sepharose (Amersham Biosciences). The column was equilibrated with buffer A $\left(50 \mathrm{mmol} \mathrm{L}^{-1}\right.$ Tris-HCl, $\mathrm{pH}=7.4,150 \mathrm{mmol} \mathrm{L}^{-1} \mathrm{NaCl}, 1 \mathrm{mmol} \mathrm{L}^{-1}$ EDTA and $1 \mathrm{mmol} \mathrm{L}^{-1}$ DTT). Recombinant Tri a 12 was eluted by a stepwise gradient of the elution buffer $\left(50 \mathrm{mmol} \mathrm{L}^{-1}\right.$ Tris-HCl, $\mathrm{pH}=7.4,150 \mathrm{mmol} \mathrm{L}^{-1} \mathrm{NaCl}$, $1 \mathrm{mmol} \mathrm{L}^{-1}$ EDTA and $6 \mathrm{~mol} \mathrm{~L}^{-1}$ urea; $25,75 \& 100 \%$ ). Fractions containing profilin were checked by SDSPAGE and dialysed against buffer A. The final dialysis step was performed against $5 \mathrm{mmol} \mathrm{L}^{-1} \mathrm{Na}$-phosphate, $\mathrm{pH}=7.2$. Protein concentration was determined using the BCA Protein Assay Reagent Kit (Pierce, Rockford, Ireland). Purified Tri a 12 was stored at $-20{ }^{\circ} \mathrm{C}$.

\section{Crystallization and X-ray Data Collection}

Crystallization conditions were screened with the sitting-drop vapour-diffusion method using Index Screen Kits (Hampton Research) at 290 K. Drops were prepared by mixing $1 \mu \mathrm{L}$ of Tri a $12\left(3.2 \mathrm{mg} \mathrm{mL}^{-1}\right.$ protein in a $50 \mathrm{mmol} \mathrm{L}^{-1}$ MES buffer $\mathrm{pH}=6.5$ ) with $1 \mu \mathrm{L}$ of the reservoir solution. The drops were equilibrated by vapour diffusion against $100 \mu \mathrm{L}$ of the reservoir solution. After one week, colourless crystals were observed in drops with reservoir conditions containing $3.5 \mathrm{~mol} \mathrm{~L}^{-1}$ sodium formate at $\mathrm{pH}=7.0$. Crystallization was then optimised by the hanging-drop vapour-diffusion method. $1 \mu \mathrm{L}$ of the protein extract was mixed with $1 \mu \mathrm{L}$ of different reservoir solutions containing sodium formate in a concentration range from 3.2 to $3.7 \mathrm{~mol} \mathrm{~L}^{-1}$ and at $\mathrm{pH}$ values between 6.0 and 7.5. The drops were equilibrated at $290 \mathrm{~K}$.

Before data collection the crystals were transferred to a cryoprotectant solution prepared by mixing the corresponding reservoir solution with glycerol in a

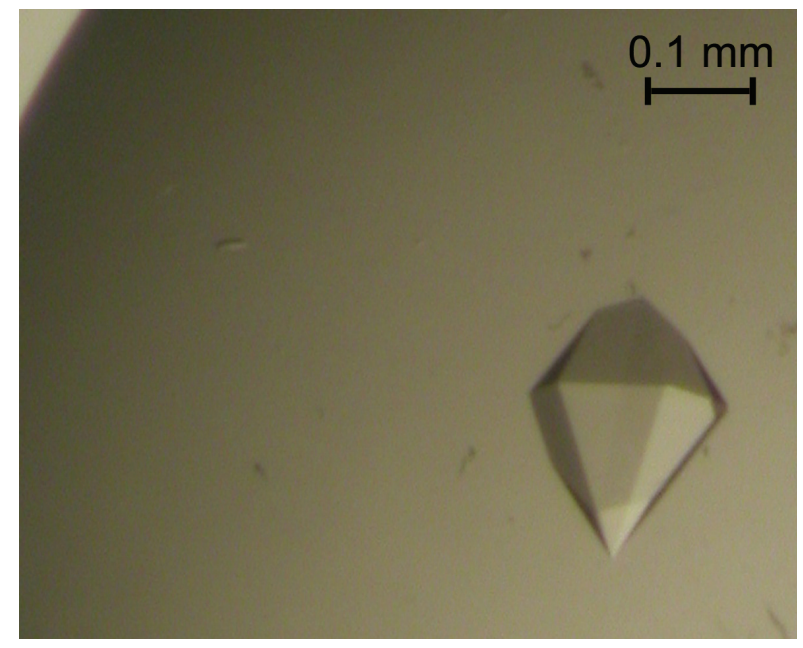

Figure 1. Crystal of wheat profilin. 


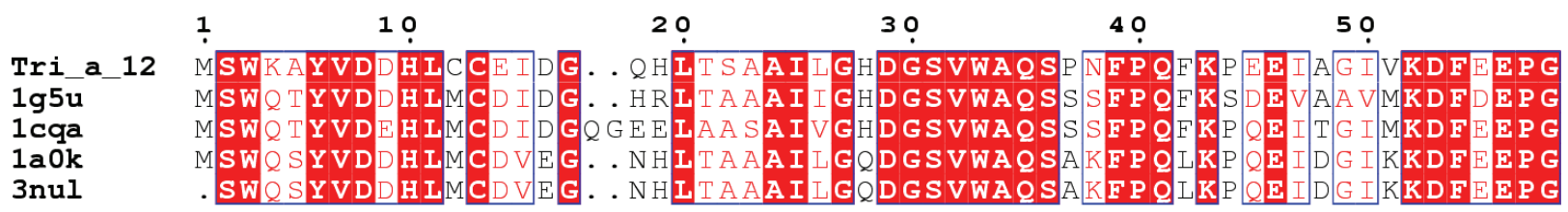

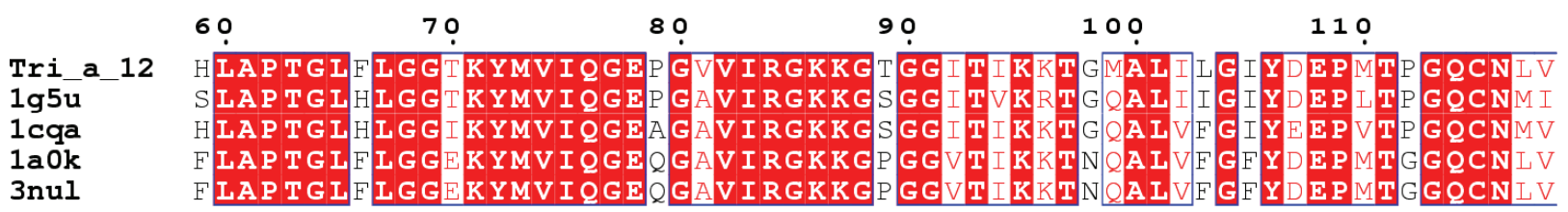

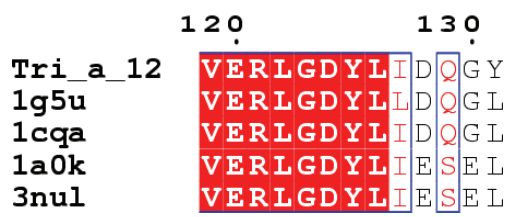

Figure 2. Sequence alignment of wheat profilin Tri a 12 and the other plant profilins with determined 3D structure. Tri a 12: wheat (Triticum aestivum) profilin Tri a 12 (FM164277); 1g5u: latex (Hevea brasiliensis) profilin Hev b 8; 1cqa: birch (Betula pendula) pollen profilin; ${ }^{17}$ 1a0k and 3nul: profilin I from Arabidopsis thaliana. ${ }^{16}$ The figure was prepared using ESPript. ${ }^{25}$

volume ratio 70:30. After a few seconds, the crystals were picked up with a nylon loop and flash-cooled at $100 \mathrm{~K}$ in a nitrogen-gas stream. A complete diffraction data set was collected on an in-house Oxford Diffraction Xcalibur Nova R diffractometer with a microfocus tube with $\mathrm{Cu} \mathrm{K} \alpha$ radiation $(\lambda=1.5418 \AA)$ and a CCD detector. A total of 322 frames were collected by $\omega$-scans at three different crystal orientations with a $0.75^{\circ}$ oscillation angle and an exposure time of $90 \mathrm{~min}$. The data were indexed, integrated and scaled using the CrysAlis software package. ${ }^{19}$ Other crystallographic calculations were performed by programs from the CCP4 program suite: ${ }^{20}$ the molecular replacement was done in PHAS$\mathrm{ER}^{21}$ using the model prepared by CHAINSAW. ${ }^{22}$

\section{RESULTS AND DISCUSSION}

Wheat profilin was expressed in E. coli and purified from the soluble fraction by affinity chromatography. $\mathrm{N}$-terminal sequencing of the purified protein batch resulted in the first five (5) amino acid residues matching the published wheat profilin sequence (SWKAY) with the initial methionine being cleaved off by the endogenous methionine aminopeptidase according to the side chain length of the penultimate amino acid. ${ }^{23}$ Mass spectrometry analysis of purified recombinant Tri a 12 yielded an intact molecular weight of $14032 \mathrm{Da}$, differing in only $1 \mathrm{Da}$ with the theoretical data of $14031 \mathrm{Da}$.
Structural integrity was investigated by circular dichroism and compared to the natural counterpart and birch pollen profilin. ${ }^{24}$ Recombinant Tri a 12 showed intact secondary structures of mixed alpha helices and beta sheet elements characteristic for members of the profilin protein family. This well characterized batch of purified recombinant wheat profilin was then used for crystallization.

Crystals of wheat profilin with maximal dimensions up to $0.3 \mathrm{~mm}$ were observed after one week at 290 $\mathrm{K}$ for reservoir solutions containing $3.2-3.7 \mathrm{~mol} \mathrm{~L}^{-1}$ sodium formate and $50 \mathrm{mmol} \mathrm{L}^{-1}$ HEPES-NaOH buffer, $\mathrm{pH}=7.5$ (Figure 1). A complete and redundant diffraction data set was collected from a single crystal with dimensions of $0.2 \times 0.2 \times 0.3 \mathrm{~mm}^{3}$. The crystallographic data and data-reduction statistics are provided in Table 1. The systematic absences of diffraction maxima and $R_{\text {int }}$ values suggested four possible space groups $\left(P 3_{1}, P 3_{2}, P 3_{1} 21\right.$, and $\left.P 3_{2} 21\right)$. The space-group ambiguity was resolved by molecular replacement trials in PHASER. ${ }^{21}$

Up to now only three structures of plant profilins have been published: latex (Hevea brasiliensis) profilin Hev b 8 (PDB code: 1g5u; 3.1 Å resolution); birch (Betula pendula) pollen profilin (PDB code: $1 \mathrm{cqa} ; 2.4 \AA$ resolution) ${ }^{17}$ and thale or mouse-ear cress (Arabidopsis thaliana) profilin I (two structures, PDB codes: 1a0k and 3nul at 2.2 and $1.6 \AA$, respectively). ${ }^{16}$ The search model for the molecular replacement was prepared from 
the latex (Hevea brasiliensis) profilin Hev b 8 structure, which shares $78 \%$ identical residues with wheat profilin (Tri a 12; Figure 2). In the molecular-replacement search model, all non-conserved residues in the chain A of latex profilin were pruned to the last common atom of wheat profilin by CHAINSAW. ${ }^{22}$ The distinctly best solution was found for the space group $P 3_{2} 21$ (rotation function $Z$-score $=6.7$, translation function $Z$ score $=17.0, R$-factor $=43.7 \%$ ). With one protein molecule in the asymmetric unit, the Matthews coefficient $\left(V_{\mathrm{M}}\right)$ was calculated to be $2.9 \AA^{3} \mathrm{Da}^{-1}$ which gives the estimated solvent content of $58.2 \%{ }^{26}$ Refinement of the crystal structure, as well as further optimization of the cryoprotectant solution and crystal diffraction quality is under way.

Acknowledgements. This work was in part funded by the EC through the EuroPrevall project (FOOD-CT-2005-514000), by CEEPUS CII-HU-0010-04-0910 and by the Ministry of Science, Education and Sports of the Republic of Croatia (Grant No. 119-1193079-1084). C. E. thanks the Austrian Academy of Sciences (ÖAW) for providing her a scholarship to complete her doctoral thesis. The authors are grateful to Dr Marija Luić and Dr Zoran Štefanić (Ruđer Bošković Institute) for time on the Oxford Diffraction Xcalibur Nova $\mathrm{R}$ diffractometer.

\section{REFERENCES}

1. EFSA. Opinion of the Scientific Panel on Dietetic Products, Nutrition and Allergies on a request from the Commission relating to the evaluation of allergenic foods for labelling purposes (Request N EFSA-Q-2003-016). (2004) The EFSA Journal 32, 1-197.

2. R. Houba, G. Doekes, and D. Heederik (1998) Am. J. Ind. Med. 34, 529-546.

3. I. Sander, A. Flagge, R. Merget, T. M. Halder, H. E. Meyer, and X. Baur, J. Allergy Clin. Immunol. 107 (2001) 907-913.

4. D. Mittag, B. Niggemann, I. Sander, I. Reese, E.-M. Fiedler, M. Worm, S. Vieths, and G. Reese, Mol. Nutr. Food Res. 48 (2004) 380-389.

5. A. S. Tatham and P. R. Shewry, Clin. Exp. Allergy, 38 (2008) 1712-1726.

6. P. Sotkovsky, M. Hubalek, L. Hernychova, P. Novak, M.
Havranova, I. Setinova, A. Kitanovicova, M. Fuchs, J. Stulik, and L. Tuckova, Proteomics 8 (2008) 1677-1691.

7. M. Weichel, N. J. Vergoossen, S. Bonomi, J. Scibilia, C. Ortolani, B. K. Ballmer-Weber, E. A. Pastorello, and R. Crameri, Allergy 61 (2006) 128-135.

8. C. Constantin, S. Quirce, M. Poorafshar, A. Touraev, B. Niggemann, A. Mari, C. Ebner, M. Akerström, E. Heberle-Bors, M. Nystrand, and R. Valenta, Allergy 64 (2009) 1030-1037.

9. H. Breiteneder and C. Ebner, J. Allergy Clin. Immunol. 106 (2000) 27-36.

10. C. Radauer and H. Breiteneder, J. Allergy Clin. Immunol. 120 (2007) 518-525.

11. K. Hoffmann-Sommergruber and C. E. N. Mills, Anal. Bioanal. Chem. 395 (2009) 25-35.

12. R. Valenta, M. Duchene, C. Ebner, P. Valent, C. Sillaber, P. Deviller, F. Ferreira, M. Tejkl, H. Edelmann, D. Kraft, and O. Scheiner, J. Exp. Med. 175 (1992) 377-385.

13. W. Witke, Trends Cell Biol. 14 (2004) 461-469.

14. R. Valenta, M. Duchene, K. Pettenburger, C. Sillaber, P. Valent, P. Bettelheim, M. Breitenbach, H. Rumpold, D. Kraft, and O. Scheiner, Science 253 (1991) 557-560.

15. R. Asero, G. Mistrello, D. Roncarolo, S. Amato, D. Zanoni, F. Barocci, and G. Caldironi, J. Allergy Clin. Immunol. 112 (2003) 427-432.

16. K. S. Thorn, H. E. M. Christensen, R. Shigeta, D. Huddler, L. Shalaby, U. Lindberg, N.-H. Chua, and C. E. Schutt, Structure 5 (1997) 19-32.

17. A. A. Fedorov, T. Ball, N. M. Mahoney, R. Valenta, and S. C. Almo, Structure 5 (1997) 33-45.

18. M. A. Larkin, G. Blackshields, N. P. Brown, R. Chenna, P. A. McGettigan, H. McWilliam, F. Valentin, I. M. Wallace, A. Wilm, R. Lopez, J. D. Thompson, T. J. Gibson, and D. G. Higgins, Bioinformatics 23 (2007) 2947-2948.

19. Oxford Diffraction, CrysAlis Software System, Version 1.171.33, Oxford Diffraction Ltd., Xcalibur CCD System, Abingdon, Oxfordshire, UK, 2009.

20. Collaborative Computational Project, Number 4, Acta Crystal$\log r$., Sect. D 50 (1994) 760-763.

21. A. J. McCoy, R. W. Grosse-Kunstleve, P. D. Adams, M. D. Winn, L. C. Storoni, and R. J. Read, J. Appl. Crystallogr. 40 (2007) 658-674.

22. N. Stein, J. Appl. Crystallogr. 41 (2008) 641-643.

23. P. H. Hirel, M. J. Schmitter, P. Dessen, G. Fayat, and S. Blanquet, Proc. Natl. Acad. Sci. USA 86 (1989) 8247-8251.

24. A. I. Sancho, K. Hoffmann-Sommergruber, S. Alessandri, A. Conti, M. G. Giuffrida, P. Shewry, B. M. Jensen, P. Skov, and S. Vieths. Clin. Exp. Allergy 40 (2010) 973-986.

25. P. Gouet, X. Robert, and E. Courcelle, Nucleic Acids Res. 31 (2003) 3320-3323.

26. B. W. Matthews, J. Mol. Biol. 33 (1968) 491-497. 